Short Communication

\title{
DEVELOPMENT AND VALIDATION OF REVERSED PHASE HPLC-PDA METHOD FOR THE QUANTIFICATION OF CHRYSIN IN SOLID LIPID NANOPARTICLES
}

\author{
ANUJ GARG ${ }^{1 *}$, GOPAL PRASAD AGRAWAL ${ }^{1}$, SHAHADALI K. ${ }^{2}$
}

1Institute of Pharmaceutical Research, GLA University, 17 Km Stone, NH-2, Mathura-Delhi Road, P. O. Chaumuhan, Mathura 281406, (U. P.) India, ${ }^{2}$ National Institute of Pharmaceutical Education and Research (NIPER), ITI Compound, Raebareli 229010, (U. P.) India

Email: anuj.garg@gla.ac.in

Received: 02 May 2019, Revised and Accepted: 04 Jul 2019

\section{ABSTRACT}

Objective: The main aim of the present study was to develop and validate a simple, precise and accurate Reversed-Phase HPLC-PDA method for the quantitative determination of Chrysin in solid lipid nanoparticles (SLNs).

Methods: The RP-HPLC-PDA system equipped with a C-18 reversed-phase column $(250 \times 4.6 \mathrm{~mm}$, particle size $5 \mu \mathrm{m})$ was employed in the present study. HPLC grade methanol and water in $85: 15(\mathrm{v} / \mathrm{v})$ ratio was selected as the mobile phase at flow rate of $1 \mathrm{ml} / \mathrm{min}$ under an ambient column oven temperature. The detection wavelength was kept at $268 \mathrm{~nm}$. Validation of developed method was performed according to the ICH guidelines.

Results: The developed reversed-phase HPLC-PDA method was found to be linear in the concentration range of $0.2-10 \mu \mathrm{g} / \mathrm{ml}$ with a correlation coefficient of 0.999 . The method was also observed to be precise with \% relative standard deviation (RSD) below $2 \%$. The limit of detection and limit of quantification of this method were found to be $0.05 \mu \mathrm{g} / \mathrm{ml}$ and $0.14 \mu \mathrm{g} / \mathrm{ml}$, respectively. The percent recovery of the developed method was estimated to more than $99 \%$.

Conclusion: The developed HPLC method can be utilized for the determination of Chrysin with a high degree of accuracy, precision, robustness, specificity in solid lipid nanoparticles in the presence of excipients.

Keywords: Chrysin, Solid Lipid Nanoparticle, Quantitative Analysis, Isocratic Reverse Phase High-Performance Liquid Chromatography (RP-HPLC)

(C) 2019 The Authors. Published by Innovare Academic Sciences Pvt Ltd. This is an open access article under the CC BY license (http://creativecommons.org/licenses/by/4.0/) DOI: http://dx.doi.org/10.22159/ijap.2019v11i5.33904

Chrysin (5, 7-dihydroxyflavone) is a flavonoid and a primary active chemical constituent of the Indian trumpet trees (Oroxylum indicum). It is also found in chamomile, in the mushroom Pleurotus ostreatus, propolis and in honey [1].

Previous studies also revealed the presence of high Chrysin content (approximately $28 \mathrm{~g} / \mathrm{l}$ ) in propolis while the Chrysin content in honeydew and forest honey was found to be $0.10 \mathrm{mg} / \mathrm{kg}$ and 0.53 $\mathrm{mg} / \mathrm{kg}$, respectively [2-3]. Chrysin was reported to have many biological activities like anti-oxidant, anti-inflammatory, anti-diabetic, anti-cancer, anti-hemolytic, anti-hypertension and neuroprotection [4, 5]. But the therapeutic potential of Chrysin is severely limited by its poor oral bioavailability $(\mathrm{F} \leq 0.02 \%)$ which is because of its poor aqueous solubility $(2-5 \mu \mathrm{g} / \mathrm{ml})$ and extensive pre-systemic metabolism in the intestine and the first-pass metabolism in the liver [6-8]. Nanotechnology is widely used as an excellent tool to improve the oral bioavailability of flavonoids like quercetin, apigenin, rutin etc. Nanoparticles can also influence the pharmacokinetics of drugs which affect their bioavailability, metabolism as well as biodistribution mainly due to their composition and submicron size $[9,10]$.

Poorly aqueous soluble drugs often exhibit low bioavailability as their absorption can be kinetically-limited by low rates of dissolution and capacity-limited by poor solubility. Lipid-based formulations can reduce the inherent limitations of slow and incomplete dissolution of water-insoluble drugs, and facilitate the formation of solubilized phases from which absorption may occur [11]. Solid lipid nanoparticles (SLNs) have been proposed as an alternative drug carrier system to other novel delivery approaches, such as microemulsions, microsphere, liposomes and polymeric nanoparticles, due to various advantages, including feasibility of incorporation of lipophilic and hydrophilic drugs, improve physical stability, low cost, ease of scale-up and manufacturing [12] . Nanoemulsions are reported to be less physically stable while polymeric nanoparticles are proved to be more toxic than SLN [13-16]. Further SLNs are easier to prepare and offers more stability than other delivery systems [17].

Chrysin loaded solid lipid nanoparticles (Ch-SLNs) has been developed and evaluated for their physiochemical characterization and in vitro anticancer activity against MCF-7 breast cancer cells by the authors in their previous work. Chrysin loaded SLNs exhibited higher in vitro anticancer activity against the breast cancer cell line as compared to that of bulk chrysin [18].

The literature survey revealed that various analytical methods have been depicted for the determination of Chrysin and their derivatives in natural products either individually or in the presence of other phytochemicals by using HPLC $[19,20]$. However, no reports were available as yet on reversed-phase HPLC equipped with photodiode array detector (RP-HPLCPDA) based methods for the quantification of Chrysin in solid lipid nanoparticles. Moreover, none of the methods were available for quantification of Chrysin in solid lipid nanoparticles where a high specificity is required to surmount the likely interference of the excipients. Hence, the objective of the present work was to develop an accurate, precise, robust, specific and suitable RP-HPLC based method to quantify Chrysin in solid lipid nanoparticles to determine entrapment efficiency, total drug content with high specificity and prevent interference of excipients. The different analytical performance parameters such as linearity, precision, accuracy, reproducibility, the limit of detection (LOD) and limit of quantification (LOQ) were determined as per ICH Q2 (R1) guidelines $[19,21]$.

Chrysin ( $\geq 98 \%$ ) and D- $\alpha$-Tocopherol polyethylene glycol 1000 succinate (TPGS) was procured from Sigma Aldrich (Mumbai, India) while stearic acid and Poloxamer 188 (Lutrol F-68) was purchased from Hi-media (Mumbai, India). All HPLC grade solvents and chemicals of analytical grade were purchased from Merck Specialties (Mumbai, India).

Modified hot high shear homogenization ultrasonication method was used to prepare Chrysin loaded SLNs as reported earlier [18]. Briefly, $400 \mathrm{mg}$ of solid lipid (stearic acid) was melted and oleic acid (20\% of stearic acid) was added in the molten lipid and taken as lipid matrix for preparation of solid lipid nanoparticles. Co-surfactant like (TPGS) was dispersed in the lipid melt and then dissolved in an organic solvent (acetone) and then Chrysin was added to the lipid solution. Organic solvent was evaporated on a water bath. Further, lipid phase 
was homogenized in a hot aqueous phase containing $1 \% \mathrm{w} / \mathrm{v}$ Poloxamer 188 by utilising high shear homogenizer at $12000 \mathrm{rpm}$ for $5 \mathrm{~min}$. Resulting dispersion was sonicated using a probe sonicator for 15 min ( 3 cycles, 5 min of each) at $40 \%$ amplitude and $1 \mathrm{~s}$ pulse on-off time. Blank SLNs were prepared using the same manner excluding the drug. Chrysin loaded solid lipid nanoparticles were successfully prepared by using hot high shear homogenization method. The particle size, polydispersity index and zeta potential of prepared solid lipid nanoparticles was found to be $358 \pm 04 \mathrm{~nm}, 0.268 \pm 0.03$ and$51.0 \pm 2 \mathrm{mV}$, respectively. The solid-state characterization and morphology studies of prepared Ch-SLNs were carried out along with in vitro anticancer activity against MCF-7 cell lines. These results were published in the previous work of authors [18].

Waters HPLC system consisted of a Waters 515 HPLC binary pumps, degasser, Waters 2998 photodiode array (PDA) detector and waters column oven. Samples were separated on SunFire C18 column (4.6 $\mathrm{mm} \times 250 \mathrm{~mm}, 5 \mu \mathrm{m}$ ) at ambient temperature. All the parameters of HPLC were controlled and the results were integrated with Empower software.

HPLC grade methanol and water in the ratio of 85: 15 was used as mobile phase. Mobile phase was filtered through $0.22 \mu$ PTFE filters and degassed by sonicating for $5 \mathrm{~min}$ before use. The flow rate and injection volume were kept at $1.0 \mathrm{ml} / \mathrm{min}$ and $20 \mu \mathrm{L}$, respectively. The column effluent was monitored at $268 \mathrm{~nm}$ by PDA detector. Initially, a mobile phase mixture of methanol and water was used to develop the HPLC method of Chrysin in SLN. However, the method has not proved repeatability or accuracy. Consequently, different ratios of methanol and water as mobile phase were used. The best peak with respect to width and symmetry was observed with a mobile phase of methanol and water in the ratio of $85: 15(\mathrm{v} / \mathrm{v})$ and a flow rate of $1.0 \mathrm{ml} / \mathrm{min}$. The peak was detected at $4.6 \mathrm{~min}$ (fig. 1) and chromatographic conditions were summarized in table 1 .

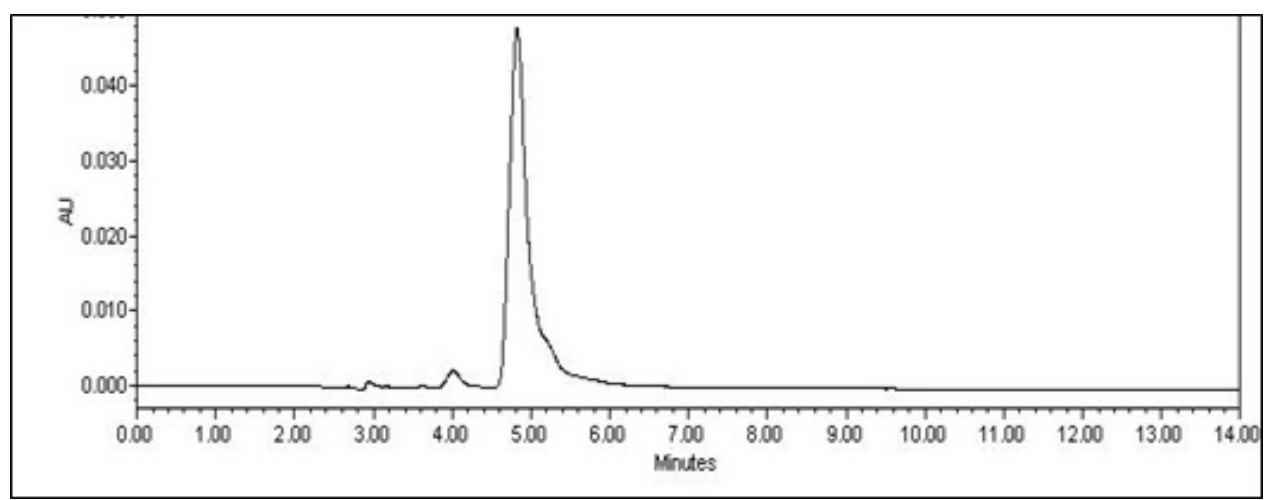

Fig. 1: Representative HPLC chromatogram of a $3 \mu \mathrm{g} / \mathrm{ml}$ Chrysin standard solution

Table 1: Chromatographic conditions

\begin{tabular}{ll}
\hline Composition & Value \\
\hline Column & SunFire C18 reverse phase column $(250 \times 4.6 \mathrm{~mm}$, particle size $5 \mu \mathrm{m})$ \\
Flow rate & $1 \mathrm{ml} / \mathrm{min}$ \\
Retention time & $4.57 \pm 0.12 \mathrm{~min}$ \\
Detector & PDA detector (Waters 2998) \\
Detection wavelength & $268 \mathrm{~nm}$ \\
Injection volume & $20 \mu \mathrm{L}$ \\
Temperature & Ambient temperature \\
Elution type & Isocratic \\
Run time & 14 min \\
\hline
\end{tabular}

Chrysin standard and Chrysin loaded SLNs equivalent to $10 \mathrm{mg}$ was weighed accurately and transferred to $100 \mathrm{ml}$ volumetric flask. A small volume of HPLC grade methanol was used to dissolve chrysin and further diluted up to mark with the same solvent to get a concentration of $100 \mu \mathrm{g} / \mathrm{ml}$. The solution was filtered through 0.22 $\mu \mathrm{m}$ syringe filter and further diluted with methanol to yield a different concentration.

The developed HPLC method was validated for linearity, specificity, precision, accuracy and robustness as accordance to ICH guidelines [21]. Linearity was evaluated in the range of $0.2-10 \mu \mathrm{g} / \mathrm{ml}$. Different concentrations of chrysin were prepared like $0.2,0.3,0.5,0.8,0.9,1$, $2,4,5,6,7$ and $10 \mu \mathrm{g} / \mathrm{ml}$. All the solutions were filtered with 0.22 $\mu \mathrm{m}$ pore size PVDF Whatman syringe filter prior to injection. Peak area versus concentration was subjected to linear regression analysis and the slope, intercept and correlation coefficient for the calibration was determined. Correlation coefficient is a statistical tool used to measure the degree or strength of this type of relationship. The linear regression data for the calibration curve with equation $\mathrm{Y}=136492 \mathrm{X}+19282$ (Where $\mathrm{Y}$ is the peak area (mAU) and $\mathrm{C}$ is the concentration $(\mu \mathrm{g} / \mathrm{ml})$ of the standard solution demonstrated a good linear relationship over the concentration range of 0.2 to $10 \mu \mathrm{g} / \mathrm{ml}$. A good linearity was established by a correlation coefficient $\left(\mathrm{R}^{2}\right)$ value of $0.9992 \pm 0.0001$. A high correlation coefficient value (a value very close to 1.0 ) indicated a high level of linear relationship between the concentration of Chrysin and peak area [22].

Limits of detection and quantification were determined from the calibration curve using the following equations:

$$
\begin{gathered}
L O D=\frac{3.3 \sigma}{S} \\
L O Q=\frac{10 \sigma}{S}
\end{gathered}
$$

Where $\sigma$ is the standard deviation of intercepts and $S$ is the slope of the calibration curve [23].

The LOD and LOQ were found to be 0.05 and $0.14 \mu \mathrm{g} / \mathrm{ml}$, respectively. This indicated that the developed method was more sensitive towards analyte as compared to previously reported methods [24].

The specificity of the method was ascertained by analysing the standard drug and sample. The peak for Chrysin in SLN samples was confirmed by comparing the Retention time (RT) values with that of 
the standard. The peak purity of Chrysin was assessed by comparing the spectra at three different levels, that is, peak start, peak apex, and peak end positions of the spectrum. The specificity is considered the first analytical validation step, it must be ensured that the components of the formulation such as excipients, does not interfere in the quantification of the drug. The specificity of the method was evaluated by comparing the chromatograms of Chrysin extracted from solid lipid nanoparticles with that of standard solution of Chrysin. The representative chromatogram of the Chrysin sample (fig. 2) showed the peak at approximately $4.6 \mathrm{~min}$, which was in agreement with that obtained for the standard (fig. 1). No peaks at this retention time were observed in the chromatogram of the blank SLNs (fig. 3), which indicated no interference in the quantitative determination of Chrysin from the formulation.

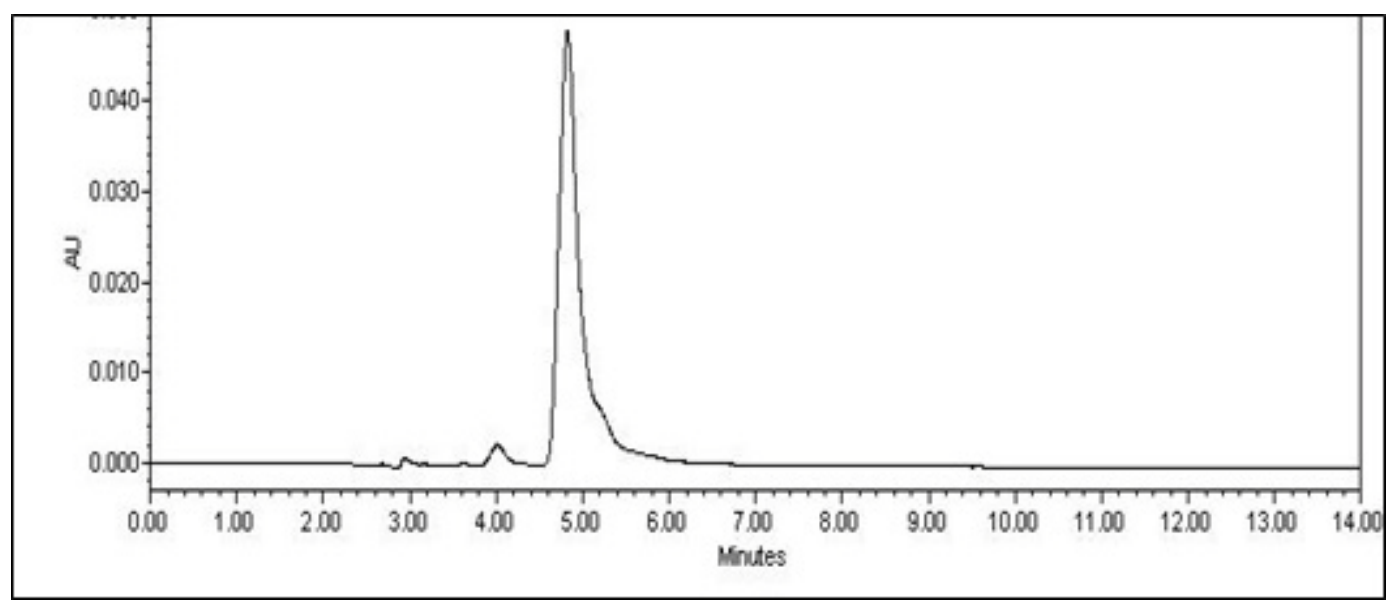

Fig. 2: Chromatogram of chrysin from solid lipid nanoparticles

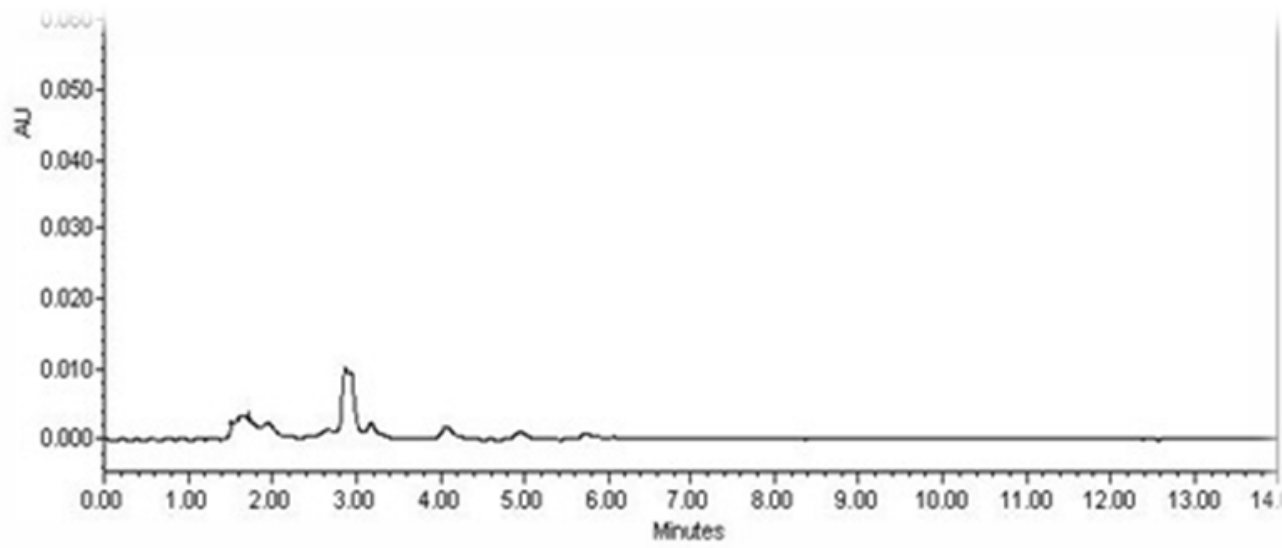

Fig. 3: Chromatogram of blank SLNs

The method was also validated in terms of repeatability (intraday) and intermediate precision (inter-day) as per ICH guidelines [21]. Three concentrations of Chrysin (1, 6 and $10 \mu \mathrm{g} / \mathrm{ml})$ were prepared in triplicate and analysed to evaluate the intra-day and inter-day precision. The precision results were reported as the standard deviation (SD) and the percent relative standard deviation (\%RSD). The result of repeatability and intermediate precision were found within the limik(2 \%RSD). The \% RSD of intra-day precision and inter-day were found at three different concentration $(1,6$ and $10 \mu \mathrm{g} / \mathrm{ml})$ less than $2 \%$. These values (table 2) were well within the generally acceptable limit of not more than $2 \%$. The result confirmed the good precision of the developed method of the assay [25]. The responses were calculated for each concentration as shown in table 2 .

Table 2: Repeatability and intermediate precision of developed HPLC method

\begin{tabular}{llll}
\hline Concentration $(\boldsymbol{\mu g} / \mathbf{m l})$ & Repeatability & \multicolumn{2}{c}{ Intermediate precision } \\
\cline { 2 - 4 } & Peak area $\left(\boldsymbol{\mu v} \mathbf{v}^{*} \mathbf{s e c}\right)$ & \%RSD & Peak area $\left(\boldsymbol{\mu v} \mathbf{s e c}^{*} \mathbf{\text { RSD }}\right.$ \\
\hline 1 & $158647.5 \pm 389.6$ & 0.24 & $159412 \pm 456$ \\
6 & $849458 \pm 5566.3$ & 0.66 & $846701 \pm 1667.36$ \\
10 & $1403101 \pm 12131.8$ & 0.86 & $1282212 \pm 18252.5$ \\
\hline
\end{tabular}

Data given in mean $\pm \operatorname{SD}(n=3)$

Accuracy was determined by recovery studies via standard addition method. Pre-analysed samples of the formulation of known quantity were spiked by $50 \%, 100 \%$ and $150 \%$ in standard chrysin solution $(3 \mu \mathrm{g} / \mathrm{ml})$. Each solution of three different concentrations was 
prepared in triplicate and suitably diluted and analysed. Recovery studies can also be considered as suitable method to determine drug content precisely in formulated Chrysin loaded solid lipid nanoparticles. The accuracy was assessed by calculating the percent recovery and the \% RSD of the mean concentration of the analyte. The detailed results are presented in table 3 . The mean percent recovery of Chrysin at three different level $(50 \%, 100 \%$ and $150 \%)$ from the samples were found to be $102.66 \%, 99.72 \%$ and $100.29 \%$ respectively, which indicated a good agreement between the experimental and theoretical values [24].

Robustness of the method was evaluated by deliberately introducing very small changes in the analytical methodology at a single concentration level. Robustness of the proposed method was determined in different ways, i.e., by making deliberate changes in the mobile phase ratio $( \pm 2 \%)$, flow rate $( \pm 0.1 \mathrm{ml} / \mathrm{min}$.), and detection wavelength $( \pm 2 \mathrm{~nm})$ of analysis. The percentage of relative standard deviation (\%RSD) of the experiment was calculated to assess the robustness of the method [21]. Factors such as the tailing factor, theoretical plates and the capacity factor were taken into consideration for testing the system suitability and system performance.

The evaluation of robustness was based on the percent RSD values obtained using different parameters for the flow rate of the mobile phase. The method was robust concerning these alterations in chromatographic parameters (table 4). The retention time was found to be deviated less than $5 \%$ from the actual value of 4.59 to $4.68 \mathrm{~min}$. Peak tailing was influenced from 1.34 to 1.47 which indicated a good and symmetrical peak. Theoretical plates were also found to be more than 9000 above to acceptable limit $¥ 2000$ ). The results are presented in table 4.

Table 3: Recovery data for the accuracy of the HPLC method

\begin{tabular}{|c|c|c|c|c|c|}
\hline $\begin{array}{l}\text { Excess of chrysin } \\
\text { added (\%) }\end{array}$ & $\begin{array}{l}\text { Concentration of } \\
\text { sample }(\mu \mathrm{g} / \mathrm{ml})\end{array}$ & $\begin{array}{l}\text { Theoretical concentration of } \\
\text { spiked sample }(\mu \mathrm{g} / \mathrm{ml})\end{array}$ & $\begin{array}{l}\text { Concentration of spiked } \\
\text { sample }(\mu \mathrm{g} / \mathrm{ml})\end{array}$ & $\begin{array}{l}\text { Recovery } \\
(\%) \\
\end{array}$ & $\begin{array}{l}\% \\
\text { RSD } \\
\end{array}$ \\
\hline 50 & 3 & 4.50 & $4.61 \pm 0.04$ & $102.66 \pm 0.92$ & 0.90 \\
\hline 100 & 3 & 6 & $5.98 \pm 0.11$ & $99.72 \pm 1.84$ & 1.84 \\
\hline 150 & 3 & 7.50 & $7.52 \pm 0.13$ & $100.29 \pm 1.75$ & 1.75 \\
\hline
\end{tabular}

Data given in mean $\pm S D(n=3)$

Table 4: Robustness data of the HPLC method

\begin{tabular}{|c|c|c|c|c|c|c|c|}
\hline \multirow[t]{2}{*}{ Parameter } & \multicolumn{3}{|c|}{ Study Condition } & \multirow[t]{2}{*}{ Area $\left(\mu v^{*}\right.$ sec $)$} & \multirow[t]{2}{*}{ \%RSD of area } & \multirow[t]{2}{*}{ RT (min) } & \multirow[t]{2}{*}{ \% RSD of R } \\
\hline & Original & Used & Level & & & & \\
\hline \multirow{3}{*}{ Mobile phase ratio (Methanol: Water) } & $85: 15$ & $83: 17$ & -1 & $1166825 \pm 2,650.66$ & 0.23 & $4.68 \pm 0.30$ & 6.42 \\
\hline & & $85: 15$ & 0 & & & & \\
\hline & & $87: 13$ & +1 & & & & \\
\hline \multirow[t]{3}{*}{ Flow rate $(\mathrm{ml} / \mathrm{min})$} & 1.0 & 0.9 & -1 & $1278527 \pm 1985.78$ & 0.16 & $4.59 \pm 0.34$ & 7.4 \\
\hline & & 1.0 & 0 & & & & \\
\hline & & 1.1 & +1 & & & & \\
\hline \multirow{3}{*}{ Detection wavelength (nm) } & 268 & 266 & -1 & $1318881 \pm 843.66$ & 0.06 & $4.63 \pm 0.0$ & 0.0 \\
\hline & & 268 & 0 & & & & \\
\hline & & 270 & +1 & & & & \\
\hline
\end{tabular}

Data given in mean $\pm S D(n=3)$

The HPLC-PDA system with C-18 reversed-phase column $(250 \times 4.6$ $\mathrm{mm}$, particle size $5 \mu \mathrm{m}$ ) was used in the present method for the quantification of Chrysin in solid lipid nanoparticles. Methanol and water in ratio of $85: 15(\mathrm{v} / \mathrm{v})$ was selected and detection wavelength of $268 \mathrm{~nm}$ was used with a flow rate of $1 \mathrm{ml} / \mathrm{min}$. The method was validated in terms of linearity, range, accuracy, precision, specificity, robustness, detection limit, and quantitation limit according to the guidelines of the International Conference on Harmonization (ICH) and fulfilled all of the requirements to be considered a reliable method. The detection limits and quantification limits were found to be $0.05 \mu \mathrm{g} / \mathrm{ml}$ and $0.14 \mu \mathrm{g} / \mathrm{ml}$, respectively. The developed HPLC method can be successfully applied for the quantification of chrysin in other formulations including nanoparticles.

\section{AUTHORS CONTRIBUTIONS}

All the author have contributed equally

\section{CONFLICT OF INTERESTS}

Declared none

\section{REFERENCES}

1. Chen LJ, Games DE, Jones J. Isolation and identification of four flavonoid constituents from the seeds of oroxylum indicum by high-speed counter-current chromatography.J Chromatogr A 2003;988:95-105.

2. Pichichero E, Cicconi R, Mattei M, Muzi MG, Canini A. Acacia honey and chrysin reduce the proliferation of melanoma cells through alterations in cell cycle progression. Int J Oncol 2010;37:973-81.

3. Hadjmohammadi MR, Saman S, Nazari SJ. Separation optimization of quercetin, hesperetin and chrysin in honey by micellar liquid chromatography and experimental design. J Sep Sci 2010;33:3144-51.

4. Kasala ER, Bodduluru LN, Barua CC. Chrysin and its emerging antineoplastic effects. Cancer Gene Ther 2016;23:43.

5. Jung J. Emerging utilization of chrysin using nanoscale modification. J Nanomater 2016;1-7. http://dx.doi.org/10.1155/2016/2894089

6. Sun LP, Chen $\mathrm{AL}$, Hung $\mathrm{HC}$, Chien $\mathrm{YH}$, Huang JS, Huang $\mathrm{CY}$, et al. Chrysin: a histone deacetylase 8 inhibitor with anticancer activity and a suitable candidate for the standardization of chinese propolis. J Agric Food Chem 2012;60:11748-58.

7. Lirdprapamongkol K, Sakurai H, Abdelhamed S, Yokoyama S, Maruyama T, Athikomkulchai S, et al. A flavonoid chrysin suppresses hypoxic survival and metastatic growth of mouse breast cancer cells. Oncol Rep 2013;30:2357-64.

8. Walle T, Otake Y, Brubaker JA, Walle UK, Halushka PV. Disposition and metabolism of the flavonoid chrysin in normal volunteers. Br J Clin Pharmacol 2001;51:143-6.

9. Kadian R. Nanoparticles: a promising drug delivery approach. Asian J Pharm Clin Res 2018;11:30-5.

10. Dong D, Quan E, Yuan X, Xie Q, Li Z. Sodium oleate-based nanoemulsion enhances oral absorption of chrysin through inhibition of UGT-mediated metabolism. Mol Pharm 2016;14:2864-74. 
11. Humberstone AJ, Charman WN. Lipid-based vehicles for the oral delivery of poorly water soluble drugs. Adv Drug Delivery Rev 1997;25:103-28.

12. Ansari MJ, Anwer MK, Jamil S, Al-Shdefat R, Ali BE, Ahmad MM, et al. Enhanced oral bioavailability of insulin-loaded solid lipid nanoparticles: pharmacokinetic bioavailability of insulinloaded solid lipid nanoparticles in diabetic rats. Drug Delivery 2015;23:1972-9.

13. Chique KR, Puertas AM, Romero-Cano MS, Rojas C, Urbina Villalba G. Nanoemulsion stability: experimental evaluation of the flocculation rate from turbidity measurements. Adv Colloid Interface Sci 2012;178:1-20.

14. Qian C, Decker EA, Xiao H, McClements DJ. Physical and chemical stability of beta -carotene-enriched nanoemulsions: influence of $\mathrm{pH}$, ionic strength, temperature, and emulsifier type. Food Chem 2012;132:1221-9.

15. Qu J, Zhang L, Chen Z, Mao G, Gao Z, Lai X, et al. Nanostructured lipid carriers, solid lipid nanoparticles, and polymeric nanoparticles: which kind of drug delivery system is better for glioblastoma chemotherapy. Drug Delivery 2016;23:3408-16.

16. Singh RP, Ramarao P. Accumulated polymer degradation products as effector molecules in cytotoxicity of polymeric nanoparticles. Toxicol Sci 2013;136:131-43.

17. Müller RH, Radtke M, Wissing SA. Solid lipid nanoparticles (SLN) and nanostructured lipid carriers (NLC) in cosmetic and dermatological preparations. Adv Drug Delivery Rev 2002;54:S131-55
18. Shahadali K, Garg A, Wahajuddin M. Development and evaluation of Chrysin-Phospholipid complex loaded solid lipid nanoparticles-storage stability and in vitro anticancer activity. J Microencapsulation 2018;35:600-17.

19. Kim KS, Shin IS, Park Y, Lee S, Kim YB, Kim B. Highperformance liquid chromatographic analysis of chrysin derivatives on a nova-pak | C18 column. Arch Pharm Res 2002;25:613-6.

20. Pellati F, Orlandinia G, Pinetti D, Benvenutia S. HPLC-DAD and HPLC-ESI-MS/MS methods for metabolite profiling of propolis extracts. J Pharma Biomed Anal 2011;55:934-48.

21. ICH Q2(R1) Validation of analytical procedures, text and methodology. International conference on Harmonization; 2016.

22. Balaji N, Sivaraman VR, Neeraja P. A validated UPLC method for the determination of process-related impurities in the antimigraine bulk drug. J Appl Chem 2013;3:20-8.

23. Joana G, Zelia B. Validation of two spectrophotometric methods for fluoxetine quantification. Int J Pharm Pharm Sci 2016;8:72-8.

24. Sesharao M, Madhavarao V. A new validated simultaneous reversed-phase high-performance liquid chromatography assay method for estimation of two flavones (baicalein and chrysin) in API drugs. Asian J Pharm Clin Res 2018;11:351-6.

25. Krishnaphanisri P, Sundararajan R. Development and validation of new RP-UPLC method for the determination of cefdinir in bulk and dosage form. Int J Pharm Pharm Sci 2018;10:178-84. 